Revista de Economia Política, vol. 30, no 2 (118), pp. 254-270, abril-junho/2010

\title{
Weber e Schumpeter A ação econômica do empreendedor
}

\author{
ANA CRISTINA BRAGA MARTES*
}

Weber and Schumpeter: the Economic action of the entrepreneur. Is there any specificity to be raised in the relations established between entrepreneurs and institutions? Recently, the term entrepreneurship is being widely employed. Enterprising is not anymore a restricted activity to the private sector, but also the Third Sector and the Public Administration. It does not only circumscribe the space of innovation, but also of the adapting changes. In this sense, such elastic concept runs the risk to lose consistency. It seems to be appropriate, therefore, to rescue the meaning that many authors, considered classic in Social Sciences, had attributed to the subject, to show that, although deep socioeconomic transformations occurred since Schumpeter wrote the Theory of the Economic Development, is still necessary to emphasize a basic dimension of the enterprising action: resistance and institutional conflict.

Keywords: entrepreneurial Innovation; economic sociology; institutional conflict.

Jel Classification: A14.

\section{INTRODUÇÃO}

A pergunta que norteia este trabalho é: haveria alguma especificidade a ser destacada nas relações que se estabelecem entre o empreendedor típico e as instituições? Nas últimas décadas, o termo empreendedorismo vem sendo largamente empregado nos estudos de Economia, Sociologia Econômica e Administração de Empresas. Nos Estados Unidos, apenas para citarmos um exemplo, há 48 journals acadêmicos sobre este tema. Entretanto, a expansão do uso foi acompanhada de uma certa frouxidão do conceito. Empreender não é mais uma atividade restrita à iniciativa privada, pois passou a englobar o Terceiro Setor e a Administração Pú-

\footnotetext{
* Doutora em Ciência Política pela Universidade de São Paulo, é Professora Adjunta do Departamento de Gestão Pública da Escola de Administração de Empresas de São Paulo. E-mail: ana.martes@fgv.br. Submetido: Fevereiro 2008; aprovado: dezembro 2008.
} 
blica; não mais circunscreve o espaço da inovação, mas também das mudanças adaptativas, etc. Neste sentido, este artigo parte da premissa de que de tão elástico, o conceito corre o risco de perder consistência. Parece ser oportuno, portanto, resgatar o significado que um conjunto de autores considerados clássicos nas Ciências Sociais atribuíram a este termo e caracterizar de modo mais preciso seus aspectos fundamentais.

Acreditamos que o retorno aos clássicos, permitiria reconstituir o conceito de empreendedorismo para mostrar que, apesar das profundas transformações socioeconômicas ocorridas desde que Schumpeter escreveu A Teoria do Desenvolvimento Econômico, tais autores enfatizam uma dimensão fundamental da ação empreendedora: resistência e conflito institucional.

No livro O Fenômeno Fundamental do Desenvolvimento Econômico Schumpeter faz uso da categoria empreendedor, para mostrar os limites da teoria econômica neoclássica, especialmente sua incapacidade para incorporar e a análise o fenômeno do desenvolvimento. A teoria do equilíbrio geral não incorpora a descontinuidade: "O desenvolvimento, no sentido em que o tomamos, é um fenômeno distinto, inteiramente estranho ao que pode ser observado no fluxo circular ou na tendência para o equilibro. É uma mudança espontânea e descontínua nos canais do fluxo, perturbação do equilíbrio que altera e desloca para sempre o estado de equilíbrio previamente existente. Nossa teoria do desenvolvimento não é nada mais do que um modo de tratar este fenômeno e os processos a ele inerentes" (Schumpeter, 1985, p. 47). Seu alvo é claro: o economista Walras, o mais ilustre representante da Escola Austríaca de sua época. Para Schumpeter, inovar produz tanto desequilíbrio quanto desenvolvimento (diferente de crescimento econômico enquanto mero aumento do capital), numa situação específica em que a competição moderna entre os capitalistas não se dá por meio do preço, mas sim da tecnologia.

Acreditamos haver, neste livro, quatro pontos fundamentais concernentes às relações entre ação empreendedora e economia: 1) quanto à metodologia, Schumpeter (e também Weber) define o indivíduo (empreendedor) como unidade básica de análise, mas o empresário é também concebido como um tipo ideal e ente portador de interesses, vontade e intencionalidade. Contudo - e este ponto é fundamental — trata-se de um indivíduo socializado e não atomizado, tal como concebido pela Teoria Econômica à qual Schumpeter se opõe; 2) a inovação é o elemento dinâmico da economia, consequentemente o papel do empreendedor é fundamental na promoção do desenvolvimento econômico; 3) o empresário inovador é um tipo específico de agente, diferente do mero capitalista, pois ele decide racionalmente com base em valores (inovação), mas que também é guiado pela paixão (desejos e conquistas) e é, necessariamente, um líder; 4) o aspecto institucional é duplamente fundamental: seja pelo apoio, seja pela oposição. As instituições de crédito, as instituições políticas e econômicas, pela suas funções de taxar juros e disponibilizar capital, oferecem base de sustentação à ação empreendedora e ajudam a alavancar um novo ciclo de crescimento, pois a origem do capital empregado não advém da poupança, mas sim do crédito. Contudo, é justamente das instituições (valores e 
organizações) que virá um forte movimento de oposição à ação empreendedora. As origens e pontos de irradiação desta oposição são institucionais.

$\mathrm{Na}$ medida em que o autor enfatiza a dimensão do conflito entre o empreendedor e as instituições, ele opera uma espécie de deslocamento analítico no campo institucional: do empresário "produzido" pelas ou "fruto" das instituições, para o empresário que age, resiste e luta contra elas (sem o que não se viabiliza a inovação). Como resultado desse processo, o empresário pioneiro é aquele que supera obstáculos e resistências para impor novos padrões de combinação dos meios de produção. Destruição de velhos padrões gera desequilibro entre as instituições econômicas, assim como pressões para novos padrões de conformidade — até atingir o ponto de uma nova situação de equilíbrio.

São estes os pontos desenvolvidos na primeira parte deste ensaio, onde buscamos estabelecer as relações conceituais e metodológicas entre Weber e Schumpeter. Em seguida, buscamos sintetizar um conjunto de críticas recentemente apresentadas ao trabalho de Schumpeter por autores ligados à Teoria (neo)Institucional e Sociologia Econômica. Schumpeter é criticado por atribuir ênfase ao indivíduo em detrimento das instituições (Aldrich, 2005). De acordo com Devine (2002) a firma (ou organização) é apenas um veículo no modelo schumpeteriano e, em decorrência desta posição, Schumpeter constrói um empreendedor com qualidades extra-humanas: ora se aproxima do "herói", ora se aproxima de uma espécie de "super-homem. Considero ser possível conceber esta questão de um modo um pouco diferente. Qual seja, se Schumpeter mantém como ponto de partida a ênfase no empreendedor, mas como um tipo social, ou coletivo, isso significa que: 1) não se trata de descrever um indivíduo único e isolado, mas sim um ser social "típico", no sentido weberiano; 2) o instrumento metodológico utilizado, o individualismo, é trabalhado de maneira complementar à análise tipológica; 3) o tipo social a que se chama empreendedor é portador de um quadro cognitivo diferenciado e sofre resistência de um conjunto de instituições (cultura, hábito e tradição) apesar de também contar com o apoio imprescindível de outras tantas instituições.

Finalmente concluímos que, se optamos por trabalhar com a definição de empreendedorismo como sendo pioneirismo e inovação, os trabalhos recentes falham na sua formulação teórica, exatamente naquele ponto em que Schumpeter é bem-sucedido: na explicação de mudanças radicais. E isso, conforme veremos, só é possível porque seu conceito de empreendedor está fortemente baseado em uma teoria da ação que, segundo acreditamos, é de cunho weberiano.

\section{DE VOLTA AOS CLÁSSICOS - EMPREENDEDORISMO E CONFLITO INSTITUCIONAL}

\section{Primeiro argumento: grandes inovações geram grandes oposições}

Mesmo que não tenham tomado o empreendedorismo como tema central de análise, importantes trabalhos clássicos da Sociologia referiram-se a ele com o 
objetivo de chamar atenção para o conflito fundamental do século XIX: inovação versus tradição. Interessados em desvendar as consequências da sociedade industrial, buscaram explicar a modernidade como um contraponto fundamental às sociedades tradicionais (ou "primitivas") em várias de suas dimensões. É assim que Weber, ao mostrar as "afinidades eletivas" entre a ética protestante e o ethos capitalista, escreve: "para saber quais as forças motrizes da expansão do capitalismo (moderno) não se precisa por em primeiro lugar a questão da origem das reservas monetárias valorizáveis como capital, e sim a questão do desenvolvimento do espírito capitalista [...] tal entrada em cena não foi pacifica. Uma onda de desconfiança, de ódio por vezes, sobretudo de indignação moral, levanta-se repetidamente contra o primeiro inovador [...] Dificilmente se permite reconhecer com suficiente imparcialidade que só uma extraordinária firmeza de caráter é capaz de resguardar um desses empresários 'novo estilo'... juntamente com a clarividência e capacidade de ação [...] lhes possibilitam angariar confiança desde logo indispensável dos clientes e operários [...] sobretudo para assumir o trabalho infinitamente mais intenso que agora é exigido do empresário e que é incompatível com um fácil gozo da vida - qualidades éticas, todavia, de um tipo especificamente diverso das que eram adequadas ao tradicionalismo de outrora" (Weber, 1981, p. 61).

Acredito ser importante pontuar cada uma das proposições extraídas deste pequeno trecho. Em primeiro lugar, a origem do capital, ou o país de origem dos capitalistas, é menos importante do que a mentalidade de seus proprietários, palavra antiga que nos dias de hoje costuma ser designado por cognição. Em segundo lugar, esta mentalidade é desafiadora de aspectos cristalizados na ordem institucional existente, por definição. Terceiro ponto, as qualidades individuais, ainda que sejam tomadas como tipos ideais, expressam fenômenos socialmente construídos: o empreendedor - tal como é aqui descrito — só é possível no capitalismo moderno. Tais qualificações são capazes de configurar contextos de relações sociais e de trocas econômicas capazes de facilitar a formação de contratos - relações baseadas em confiança - e as relações entre empreendedor e empregados. Por último, neste pequeno e denso parágrafo, Weber enfatiza uma de suas mais importantes teses: $\mathrm{o}$ capitalista moderno reinveste e faz crescer sua empresa. É para isso que trabalha e não para usufruir pessoalmente do lucro adquirido. Este homem conjuga racionalidade econômica e autointeresse com valores modernos e, nesta medida, não é um mero capitalista. Outras tentativas de diferenciar o capitalista do empreendedor podem ser encontradas em diversos trabalhos, como os de Sombart. Os "capitães de indústria”, termo correlato a empreendedores, emprega uma racionalidade diferenciada e possui características psicológicas específicas, especialmente quanto ao seguinte ponto: porque deseja a prosperidade de seu negócio, persegue uma lucratividade cada vez maior. Ou seja, é para poder alcançar sucesso em seu empreendimento que o empresário "se vê obrigado" a "perseguir o lucro". A expansão do negócio é o que move o empresário. Comparadas às atividades essenciais do capitalista do século XIX, suas atividades se mantêm, mas de forma mais ampliada e profunda: trabalham mais, calculam mais, negociam e especulam mais etc.; assim, 
os princípios para condução dos negócios mudaram: racionalização absoluta, por um lado e compulsão pelo aumento do volume dos negócios, por outro.

O empreendedor capitalista é descrito como um tipo sedutor, seja pela singularidade dos princípios que revestem sua ação, seja pela aparente — porém retumbante - "limpeza" com que esta ação é representada nos textos clássicos, e Weber é novamente um exemplo. Ao distinguir o empreendedor do burguês, que apenas age orientado pelo lucro, explora, usurpa etc. O empreendedor é portador de uma ética e esta é, sobretudo, diferente - por vezes oposta - àquela que até então caracterizara as sociedades e a ações econômicas pré-capitalistas. "Firmeza de caráter", "clarividência e capacidade de ação", obstinação pelo trabalho são qualidades combinadas que apenas o capitalista de um tipo muito especial possui. Não podemos nos esquecer, contudo, de que este homem singular é, para Weber, um tipo social. E, portanto, enganoso seria concluir que, ao tratar do tema empreendedor, Weber privilegia o indivíduo em detrimento do contexto socioeconômico ou das instituições. O empreendedor é fruto de uma sociedade especifica: a capitalista moderna. Mas, o capitalismo sobre o qual Weber se debruça, é aquele do final do século XIX, que traz impresso as marcas da resistência das instituições tradicionais de base essencialmente agrária contra a mecanização, a industrialização, e que por sua magnitude e oposição contribuíram para transformar, por vezes, o empreendedor em herói. Do ponto de vista metodológico, há dois menções importantes: o empreendedor é constituído como um tipo ideal (mentalmente construído) e a unidade de análise é o indivíduo (individualismo metodológico). Voltaremos a este ponto mais adiante, ao abordarmos Schumpeter.

A oposição entre empreendedor e tradicionalismo é tão marcante na virada do século XIX que Emile Durkheim, em um trecho de As Regras do Método Sociológico, ao falar sobre a coerção indireta para explicar que os fatos sociais são coisas no sentido de que são externos aos indivíduos também recorre à distinção entre o capitalista industrial de velho e novo estilo: "Se sou industrial, nada me proíbe de trabalhar utilizando processos e técnicas do século passado; mas, se o fizer, terei a ruína como resultado inevitável. Mesmo quando posso realmente me libertar destas regras e violá-las com sucesso, vejo-me sempre obrigado a lutar contra elas. E quando são finalmente vencidas, fazem sentir seu poderio de maneira suficientemente coercitiva, pela resistência que me opuseram. Nenhum inovador, por mais feliz, deixou de ver seus empreendimentos se chocarem contra oposições deste gênero" (Durkheim, 1978, p. 3) Observa-se que, neste caso, as instituições agem de modo a pressionar a adaptação e conformação no sentido da inovação, por um lado, mas também levantando terríveis barreiras e sansões a serem enfrentadas pelo inovador, por outro. Nem tão atrás, nem muito à frente. São pressões institucionais de tipos diferentes, mas tanto o tradicional quanto o inovador haverão de responder a elas. As instituições se impõem ao indivíduo ("de fora para dentro"), seja em forma de sanção ou de estímulo. Importante lembrar o conceito de institucionalização durkheimniano: "pode-se chamar instituição toda crença, todo comportamento instituído pela coletividade, sem desnaturar o sentido da expressão; sociologia seria então definida como a ciência das instituições, de sua gênese e de 
seu funcionamento" (Durkheim, 1978, p. 9). O ponto fundamental, neste caso, não é a repressão, coação ou coerção à ação que desafia as instituições, mas um tipo de impedimento de caráter sistêmico, não necessariamente organizacional: ausência de funcionalidade.

\section{Segundo argumento: o empreendedor desafia as instituições e cria novos padrões de conformidade}

"De tempos em tempos a vida econômica apresenta mudanças no sentido de romper com os limites tradicionais até estão estabelecidos de produção e comercialização de bens, impondo uma nova forma que futuramente se consubstanciará em uma nova tradição. Crescimento econômico pode ser adaptação, desenvolvimento, que significa aumento do volume de riquezas é outra coisa. As mudanças contínuas de transformação de uma lojinha em loja de departamentos, estão dentro da análise estática, porque descrevem um processo de expansão linear, de adaptação oferta / demanda. Mas e as mudanças descontínuas, não tradicionais, como explicá-las?" (Schumpeter, 1985).

No livro O Fenômeno Fundamental do Desenvolvimento Econômico publicado Schumpeter faz uso da categoria empreendedor, para criticar a teoria econômica neoclássica e mostrar que este modelo não é capaz de incorporar a análise da dinâmica e do desenvolvimento econômico. A teoria do equilíbrio não incorpora a descontinuidade: "O desenvolvimento, no sentido em que o tomamos, é um fenômeno distinto, inteiramente estranho ao que pode ser observado no fluxo circular ou na tendência para o equilibro. É uma mudança espontânea e descontínua nos canais do fluxo, perturbação do equilíbrio que altera e desloca para sempre o estado de equilíbrio previamente existente. Nossa teoria do desenvolvimento não é nada mais do que um modo de tratar este fenômeno e os processos a ele inerentes" (Schumpeter, 1985, p. 47). Seu alvo é claro: o economista Walras, mais ilustre representante da Escola Austríaca de sua época. Para Schumpeter, inovar produz tanto desequilíbrio quanto desenvolvimento (diferente de crescimento econômico enquanto mero aumento do capital), numa situação onde a competição moderna entre os capitalistas não se dá por meio do preço, mas sim da tecnologia.

Acredito haver, neste livro, quatro pontos fundamentais concernentes às relações entre ação empreendedora e economia: 1) a inovação é o elemento dinâmico da economia, consequentemente o papel do empreendedor é fundamental na promoção do desenvolvimento econômico; 2) o empresário inovador é um tipo específico de agente, diferente do mero capitalista, pois ele decide racionalmente com base em valores (inovação), mas que também é guiado pela paixão (desejos e conquistas) e é, necessariamente, um líder; 3) o aspecto institucional é duplamente fundamental: seja pelo apoio, seja pela oposição. As instituições de crédito, as instituições políticas e econômicas, pela sua função de taxar juros e disponibilizar capital, permitem, num primeiro momento, dar base de sustentação à ação empreendedora e, num segundo momento, alavancar um novo ciclo de crescimento (a origem do capital empregado não advém da poupança, mas sim do crédito). Por 
outro lado, é justamente das instituições (valores e organizações) que virá um forte movimento de oposição à ação empreendedora. A fonte (origem e irradiação) desta oposição é institucional; 4) quanto à metodologia, assim como para Weber, também para Schumpeter o indivíduo - o empresário concebido como um tipo ideal, portador de interesses, vontade e intencionalidade - é a unidade básica de análise. Mas, e este ponto é fundamental — trata-se de um indivíduo socializado e não atomizado, tal como concebido pela Teoria Econômica à qual, como vimos, ele se opõe.

É apenas dentro deste quadro mais amplo - que envolve características pessoais, aparatos institucionais, concepções metodológicas e um profícuo debate teórico - que se pode compreender o conceito "empreendedor schumpeteriano". Contudo, antes de chegarmos à sua definição mais precisa, é conveniente esclarecer o que não é empreendedorismo, segundo o nosso autor.

O que o empreendedor não é. Adaptar, crescer, administrar eficientemente a rotina de uma empresa não significa empreender. $\mathrm{O}$ ponto mais importante a ser resgatado é a ideia subjacente ao texto de que nenhuma das atividades citadas acima significa inovar. Se pudéssemos imaginar como estes dois conceitos se colocam numa linha contínua, teríamos adaptação em um pólo e inovação no outro - mesmo que a adaptação fosse feita no sentido de "modernizar" a produção ou a organização. Segundo Schumpeter, dada a situação de concorrência, o capitalista se adapta (constantemente) enquanto o empreendedor inova. Seguindo a mesma linha de raciocínio, a simples expansão das atividades e o crescimento de um negócio, não é, segundo Schumpeter, empreender: "As mudanças contínuas que podem eventualmente transformar uma pequena firma varejista numa pequena loja de departamentos, mediante adaptação contínua, feita em inúmeras etapas pequenas, estão no âmbito da análise 'estática'" (Schumpeter, 1985, p. 46). Ou seja, este tipo de mudança, a Teoria Econômica neoclássica possui instrumental analítico suficiente para explicar - lembremos que ele é um pluralista metodológico, ou instrumentalista (Silva, 2002). Competir para sobreviver não é empreender. Antepondo-se a Marshall, argumenta que o empresário não é o administrador de empresas, pois a este cabe apenas a mera função de tocar a rotina burocrática da organização e fazer "correções de rota", em casos de desvio. Para tocar um empreendimento no seu dia a dia, não é necessário liderar, mas apenas administrar, isto é, manter e adequar a produção. Contudo, um tipo particular de mudança, aquela capaz de provocar rupturas, revela as limitações da Teoria Econômica, porque é capaz de incorporar a dinâmica das economias e seus ciclos de desenvolvimento.

Empreender é, segundo Schumpeter, inovar a ponto de criar condições para uma radical transformação de um determinado setor, ramo de atividade, território, onde o empreendedor atua: novo ciclo de crescimento, capaz de promover uma ruptura no fluxo econômico continuo, tal como descrito pela teoria econômica neoclássica. A inovação não pode ocorrer sem provocar mudanças nos canais de rotina econômica. A definição com a qual Schumpeter trabalha é precisa. O empreendedor é aquele que realiza novas combinações dos meios produtivos, capazes 
de propiciar desenvolvimento econômico, quais sejam: 1) "introdução de um novo bem"; "introdução de um novo método de produção" 3) "abertura de um novo mercado" 6) "conquista de uma nova fonte de oferta de matérias primas ou bens semimanufaturados; 7) constituição ou fragmentação de posição de monopólio" (Schumpeter, 1985, p. 49).

Empreender é exercer uma função e não, portanto, uma é condição perene — nem para indivíduos, nem para coletividades. Desta afirmação decorrem três pontos fundamentais. Em primeiro lugar, o empreendedor não pertence a uma classe social (o que novamente o difere do capitalista) nem tampouco a um estamento pois sua posição não é fruto de herança, mas de conquista. Em segundo lugar, o empreendedor pode ser aquele que possui função de direção, mas sem que necessariamente possua título de propriedade da empresa, o que faz com que a condição social para o exercício desta função seja ampla: "chamamos de empresários não apenas o homem de negócios 'independente' em sua economia de trocas (leia-se: aquele que tem seu próprio negócio), mas todos os que de fato preenchem a função pela qual definimos o conceito, mesmo que sejam funcionários dependentes" (Schumpeter, 1985, p. 54). Por outro lado, o conceito exclui proprietários e diretores de empresas que simplesmente "operam" o negócio já estabelecido, pois nem o capitalista nem o acionista, são necessariamente empreendedores, "ainda que corram riscos e tenham o controle da propriedade" (Shumpeter, 1985, p. 54). Finalmente, se é uma função, ser empreendedor não é uma condição duradoura, pois poucos são os momentos em que inovações tão significativas e "revolucionárias" podem realmente ser levadas a cabo.

Instituição e racionalidade. Acreditamos que Schumpeter tenha se apoiado amplamente em Weber, ao abordar o empreendedor como um agente racional (racionalidade limitada), mas movido por valores. Segundo ele, o capitalista comum, cuja ação a teoria do equilíbrio é capaz de explicar, pisa num terreno seguro e habitual, pois sedimentado numa lógica consolidada. Por isso é capaz de "agir pronta e racionalmente". O empreendedor, ao contrário, negava contra a corrente. "O que anteriormente era um auxílio, torna-se um obstáculo. O que era um dado familiar, torna-se uma incógnita. Quando terminam as fronteiras da rotina, muitas pessoas não podem ir além [...] A suposição de que a conduta é rápida e racional é uma ficção em todas as situações" (Schumpeter, 1985, p. 57).

Neste ponto, a questão da institucionalização se apresenta de forma absolutamente relevante: “ $[. .$.$] o camponês vende seu novilho exatamente com tanta astúcia$ e egoísmo quanto o corretor da bolsa de valores vende a sua carteira de ações. Mas isso só vale quando um sem número de precedentes formaram a conduta através de décadas e, em seu fundamento, através de centenas e milhares de anos e eliminaram o comportamento não adequado" (Schumpeter 1985, p. 57). O que há de relevante neste caso é que a racionalidade econômica, sendo ela mesma, fruto de um longo processo de institucionalização. Não se trata de algo "natural", tampouco de uma qualidade intrínseca ao ser humano. Trata-se de um processo sociocultural, que se expande, torna-se hegemônico e, nessa medida, se "natuzaliza". Antepondo-se ao modelo de fluxo circular contínuo da teoria neoclássica, argumenta que as empresas 
novas não surgem das antigas "não é o dono de diligências que constrói estradas de ferro" (Schumpeter, 1985, p. 49). Para realizar novas combinações, o crédito é fundamental porque elas não poderiam ser financiadas pelo lucro da produção anterior, nem por simples poupança. É do "mero" capitalista que vem o crédito sendo, os bancos, as instituições financeiras primordiais que sustentam a inovação. "O banqueiro não é primariamente tanto um intermediário da mercadoria 'poder de compra', mas um produtor desta mercadoria. Contudo, como toda poupança e fundos de reserva hoje em dia afluem geralmente para ele e nele se concentra e demanda de poder livre de compra, quer já exista ou tenha que ser criado, ele substitui os capitalistas privados tornou-se seu agente; tornou-se ele mesmo o capitalista por excelência. Ele se coloca entre os que desejam formar combinações novas e possuidores dos meios produtivos. Ele torna possível a realização de novas combinações, autoriza as pessoas, por assim dizer, em nome da sociedade, formá-las. É o Éforo da economia de trocas" (Schumpeter, 1985, p. 52).

Realizar a função de combinar novos modos de produção é privilégio de poucos. Exige-se um tipo de comportamento excepcional, ou seja, obstinação acima da média, e qualidades raras, tanto intelectuais quanto psíquicas. Qual é a natureza da função do empreendedor e o tipo de qualidades requeridas para esta função? Esta pergunta deve ser respondida em três dimensões:

\section{Cognitiva e comportamental:}

a) para inovar, o indivíduo inevitavelmente escapa ao enquadramento usual dos problemas e soluções já testadas. Tal desafio o leva a planejar e racionalizar sua ação persistentemente. Entretanto, uma vez que aquilo que é realmente "novo é apenas o fruto da nossa imaginação" (Schumpeter, 1985, p. 60), riscos e incertezas fazem com que o empreendedor encontre-se nas mãos de sua própria intuição (penso que este termo é usado de modo intercambiável com antevisão, usado pelo autor). Tamanhas dificuldades, exigem esforços extras. Alcançar uma profunda compreensão intelectual sobre a realidade em que atua é a primeira grande tarefa do empreendedor; pois vê-se impossibilitado de tomar por base a "tradição cultural" e nem sequer possui "posição a recorrer" (termos empregados pelo próprio Schumpeter, 1985, p. 63).

b) enorme força de vontade, posto que "no peito de quem deseja fazer algo novo, as forças do hábito se levantam e testemunham contra o projeto em embrião" (Schumpeter, 1985, p. 61). Este ímpeto para a inovação, uma verdadeira obsessão, paradoxalmente pode ser estimulado pelas dificuldades de ordem institucionais que o próprio empreendedor enfrenta.

2. Dificuldades e habilidades

a) reação de oposição do ambiente social, mais exatamente "impedimentos legais e políticos" definem o quadro institucional 
com o qual o exercício da função empreendedora se defronta. No âmbito econômico as resistências vêm dos competidores, dos agentes com os quais precisam estabelecer relações de cooperação e dos próprios consumidores. De modo geral, prossegue o autor, trata-se de organizações novas e que competem com as antigas que desfrutam da mesma posição, sendo que na concorrência capitalista a tendência é de que as inovadoras eliminem as antigas.

b) uma vez que tais dificuldades devem ser por ele superadas, uma das mais importantes características do empreendedor é sua capacidade de liderança, pois a ele caberá orquestrar a implantação da inovação. Assim, o empreendedor não necessariamente inventa algo novo - mesmo do ponto de vista tecnológico - ele mesmo, mas sobretudo lidera um processo de inovação, ainda que não tenha sido ele a "inventar", ou descobrir tal inovação.

3) Motivação

a) sua motivação não é, preponderante, a do homem econômico, tal como preconizado pela teoria neoclássica. $\mathrm{O}$ empreendedor schumpeteriano age racionalmente, mas não orienta sua ação apenas pela razão, do mesmo modo que seu objetivo final não é apenas o lucro. Sua motivação também não é hedonista (satisfação das próprias necessidades). O sentido de sua ação deve ser buscado, antes, no "sonho e desejo de fundar um reino privado" (equivalente moderno à nobreza medieval), o "desejo de conquistar", "impulso para lutar" "provar-se superior aos outros", "alegria de criar e fazer coisas" (Schumpeter, 1985, p. 65). De modo que o lucro, ele mesmo, é sobretudo uma consequência, e tende a interpretado como "índice de sucesso e sinal de vitória". O empresário inova e, ao inovar, lidera profundas transformações. Contudo, não lidera através do convencimento sobre a conveniência de seu plano inovador ("exceto o banqueiro que deve financiá-lo") mas na medida em que obtém sucesso, configura novos padrões de produção.

Observa-se que, assim como Weber, Schumpeter busca explicar o sentido da ação do empreendedor e, exatamente por isso, motivação, cognição e impulsos outros, que não apenas o econômico, são dimensões fundamentais da análise. Contudo, quaisquer destas dimensões são concebidas como processos sociais e não puramente volição e comportamentos de caráter estritamente individual: "O processo social que racionaliza nossa vida e nosso pensamento afastou-nos do tratamento metafísico do desenvolvimento" (religioso, extra-humano). "Nenhuma experiência concreta evidencia a existência de um desenvolvimento uniforme e lin- 
ear na historia dos povos. Motivos (psicológicos) refletem mais processos sociais, do que vontade individual" (Schumpeter, 1985, p. 71)

\section{WEBER E SCHUMPETER}

O tipo de empreendedor schumpeteriano guarda uma grande distância dos empreendedores atualmente retratados na literatura em administração, principalmente porque para este autor empreender é sobretudo inovar, como vimos. E aqui não se trata de qualquer tipo de inovação, senão aquela de caráter pioneiro e transformador. O empresário pioneiro inova e lidera um processo de mudança que extrapola os domínios de seu negócio e da sua própria esfera de atuação.

Ação social, econômica e empreendedora - A inovação promovida pelo empreendedor não é incremental de nenhum tipo. O fabricante de carroças não se transformará em fabricante de automóveis, ele enfatiza. De fato, tão grande é a inovação, que dela decorre uma brutal resistência à ação do empreendedor. As dificuldades, neste sentido, esbarram inevitavelmente na dimensão institucional, em vários de seus aspectos, quais sejam, crença ou comportamento instituído pela coletividade (Durkheim), assim como organizações, poder e dominação (Weber). A aposta na inovação coloca a dimensão cognitiva como uma das principais características do empreendedor: ele é um agente econômico que vê o mundo de um outro jeito e, portanto, foge completamente do padrão "take for granted" (Berger e Luckmman, 1998), característico de processos e organizações já legitimadas.

Mas, é Weber de quem Schumpeter claramente se aproxima. No início do segundo capítulo O Fenômeno Fundamental do Desenvolvimento Econômico, Weber é citado para se explicitar o sentido da palavra racionalização ali empregada. Depois disso, nenhuma outra citação. Contudo, sabe-se que o trabalho de Schumpeter foi muito influenciado por Weber, sendo que chegaram a colaborar em algumas situações entre os anos de 1914 a 1939 (Granovetter \& Swedberg, 1992, p. 81). Acredito que Schumpeter faz uso de um tipo especificamente sociológico do individualismo metodológico (IM), que não o econômico. Para este autor, IM é um recurso metodológico com um valor prático-instrumental, e nada impede que se trate fenômenos coletivos, adotando-se a ação individual como unidade de análise. Esta é exatamente a proposta da sociologia compreensiva weberiana.

Segundo Gabriel Cohn, o elo entre tipo ideal e individualismo metodológico responde a uma necessidade lógica e encontra sua origem em um dos mais importantes elaboradores da teoria econômica neoclássica Karl Menger: "a grande contribuição de Menger [...] de que a decisão metodológica de tomar as ações e interesses individuais como unidades de análise implicam necessariamente em tratar os fenômenos mediante a construção de tipos" (Cohn, 1979, p. 71). De modo complementar a este raciocínio, a sociologia clássica alemã, escreve Boudon, é apoiada em três princípios: 1) buscar causas micro nos fenômenos macro; 2) buscar as causas nas ações dos atores, agrupação de atores em tipos. E complementa: "A metodologia de um Weber ou de um Simmel, está demasiado próxima desses prin- 
cípios para que possam evitar uma influência de Menger sobre a sociologia clássica alemã. [...] Assim como havia todos os motivos para que a sociologia francesa fosse atraída sobretudo por uma perspectiva holista, e a sociologia alemã por uma perspectiva individualista das sociedades" (Boudon, 1995, p. 32). Ainda de acordo com Boudon: "O individualismo metodológico também não implica que se conceba o ator social como que suspenso numa espécie de vazio social. Ele pressupõe, ao contrário, que o ator foi socializado está em relação com outros atores, os quais, como ele, ocupa papeis sócias, tem convicções, etc.(e que em larga medida, este contexto se lhe impõe [...] Todavia, é frequente a onfusão entre atomismo e individualismo metodológico [...] não existe portanto nenhuma contradição entre a metodologia individualista e a vocação da sociologia que é a de tratar fenômenos coletivos" (Boudon, 1995, p. 34).

$\mathrm{O}$ agente é concebido, na teoria economia ortodoxa, como um indivíduo atomizado - sem raízes, sem relacionamentos sociais - e o próprio contexto institucional desaparece. No caso da Sociologia Compreensiva, a ação individual é social na medida em que se orienta pelo comportamento de outros. "Outros" são definidos por Weber como sendo, além de outros indivíduos, uma "pluralidade de agentes desconhecidos e indefinidos" (Weber, 2000, p. 13). Ação econômica para Weber, possui, igualmente, características correlatas. Trata-se de uma ação individual, dirigida por interesses (materiais ou ideais), mas também por hábitos e sentimentos. $\mathrm{Na}$ teoria econômica, o ator é exclusivamente dirigido por interesses materiais e seu comportamento não é necessariamente orientado pelo comportamento de outros. Tradição e emoção não contam na ação, relações entre política, lei, religiões etc., são ignoradas (Granovetter \& Swedberg, 1992, p. 85 e 86). Para Weber, ação social propriamente econômica, é motivada pelo interesse e orientada para a utilidade. Porém, como toda ação social, ela é também uma ação orientada para o comportamento de terceiros: "Tal como na teoria econômica, a análise parte da ação individual orientada para a utilidade e movida principalmente pelos interesses materiais. Mas, ao contrário da Teoria Econômica, a Sociologia concebe a ação econômica como ação orientada pelo comportamento dos outros. Além disso, o hábito e as emoções podem influenciar a ação social econômica" (Granovetter \& Swedberg, 1992, p. 287).

Acredito que, por um lado, a tipologia de ação social weberiana nos ajuda a compreender o sentido (socialmente mediado) que o empreendedor atribui à sua própria ação. Por outro lado, acredito ser adequado trabalhar com o conceito de empreendedor schumpeteriano como um tipo ideal weberiano, ou seja, construção de uma tipologia analítica. Isso significa que a categoria "empreendedor schumpeteriano", peça chave no seu modelo explicativo, deve ser tomando não como uma descrição empírica, e sim como uma construção teórica. Como se sabe, são quatro os tipos de ação social para Weber: 1) racional; 2) racional com relação a valores; 3) afetiva e 4) tradicional. Apenas para relembrar, a tipologia weberiana consiste na ênfase de determinados traços da realidade até concebê-los na sua expressão mais pura, mas que jamais se apresenta assim nas situações concretas observáveis (Weber, 2000). 
O tipo de ação racional com relação a fins não é adequado para caracterizar o empreendedor schumpeteriano. O que primeiramente chama atenção na fundamentação do tipo empreendedor de Schumpeter é não ser ele o portador da racionalidade do "homem econômico" da teoria neoclássica. Aqui o ponto fundamental é, novamente, a anteposição do modelo schumpeteriano à teoria do equilíbrio estático walsariana, que tem na racionalidade instrumental e ilimitada seus pressupostos básicos. $\mathrm{O}$ empreendedor não age racionalmente instrumentalizando meios para atingir fins, de modo a maximizar seus interesses e reduzir riscos. O ambiente no qual sua ação se desenvolve é, ao contrário, marcado pela impredicabilidade, decorrente de toda e qualquer grande inovação, o que inevitavelmente reduz suas chances de levar adiante um tipo de ação puramente teleológica. No limite, a ação racional é planejada para alcançar uma situação de risco zero. Contudo, não é possível agir de modo puramente racional quando se dá um "salto no escuro", pois informações muito restritas e incompletas não permitem o exercício de tal cálculo. Ele lida, sobretudo, com a incerteza e frente a um cenário de baixa predicabilidade, faz sua aposta.

Ação tradicional, por sua vez, pode ser considerada oposta à ação empreendedora. O empreendedor não age nem por hábito, nem por qualquer tipo de impulso e/ou condicionamento à rotina ou repetição mecânica, menos ainda orientado por tradições religiosas, étnicas, familiares etc. $\mathrm{O}$ sentido de sua ação, centrado na inovação como um valor, mais se aproxima dos dois tipos de ação subsequentes.

Racional com relação a valores - $\mathrm{O}$ empreendedor age racionalmente com relação a valores, sendo que o valor que orienta sua ação está, sobretudo, na inovação. Diante do inseguro, ele fará de tudo para planejar e controlar os sua ação econômica, mas sabe que "aposta no escuro". A inovação é, portanto um fim em si mesmo, é ela que se quer atingir, junto à reputação de ser inovador.

Ação afetiva - Há uma inequívoca dimensão carismática no agente de inovação: o empreendedor lidera um processo de mudança, econômica e só assim é capaz de instituir novos padrões de produção que tenderão a se institucionalizar posteriormente. O líder empreendedor é um tipo aventureiro e carismático, características estas que são reconhecidas por vários autores (Devine, 2002, p. 442). Também por ser carismático, ele é capaz de subverter a ordem, desafiar instituições, liderar processos de mudança. Como todo líder a quem se atribui algum tipo de carisma, ele é consegue arregimentar seguidores com base no afeto e num discurso arrebatador e visionário. Ao discorrer sobre as qualidades extraordinárias do empreendedor, é o tipo carismático (weberiano) que está sendo enfatizado por Schumpeter e, portanto, não se trata - por parte do pesquisador - de tomar tais qualidades como atributos de um empreendedor concreto (empírico), mas sim de — tal como o faz Weber - explicar o carisma não como um dom que o líder possui (um atributo pessoal inato) mas uma atribuição social. O carisma é uma relação social, portanto, não há necessidade lógica de que o pesquisador reconheça no líder as qualidades que o "séquito" (conjunto de seguidores) entende que ele possui, mas sim que o analista tente compreender as condições e o porquê desta crença, investigando a relação liderança/liderados. 


\section{O método que sustenta a ênfase - um tipo diferente de agente econômico}

Se até aqui foi procedente a nossa tentativa de aproximar Weber de Schumpeter - em relação ao método (individualismo metodológico e tipo ideal) e à teoria da ação, cabe agora perguntar: qual é a ligação entre o método e a teoria do empreendedor?

Schumpeter é criticado por atribuir ênfase ao indivíduo em detrimento das instituições (ver por exemplo Devine, 2002; Aldrich, 2005). De acordo com Devine (2002) a firma (ou organização) é apenas um veículo no modelo schumpeteriano e, em decorrência desta posição, Schumpeter constrói um empreendedor com qualidades extra-humanas: ora se aproxima do "herói", ora se aproxima de uma espécie de "super-homem" (Aldrich, 2005). Considero ser possível conceber esta questão de um modo um pouco diferente. Penso que Schumpeter mantém, como ponto de partida, a ênfase no empreendedor, mas como um tipo social, ou coletivo. Isso significa que: 1) não se trata de descrever um indivíduo único e isolado, mas sim um ser social "típico", no sentido weberiano; 2) o instrumento metodológico utilizado, o individualismo, é trabalhado de maneira complementar à análise tipológica; 3) o tipo social a que se chama empreendedor é portador de um quadro cognitivo diferenciado e sofre resistência de um conjunto de instituições (cultura, hábito e tradição), apesar de também contar com o apoio imprescindível de outras tantas instituições. Nas páginas que se seguem, examinaremos os dois primeiros itens e, no final, os dois precedentes.

De que modo IM e tipo ideal se relacionam em Weber e - segundo a posição que queremos sustentar neste artigo — também em Schumpeter? Qual é a importância desta relação na teoria do empreendedor? A Sociologia Compreensiva tem por objetivo construir um modelo generalizante e abstrato (e portanto, teórico) da ação humana. O modelo schumpeteriano, por sua vez, traz em seu cerne uma teoria da ação: é preciso explicar a ação de um tipo diferente de agente econômico, tipo esse que, até então, a teoria econômica desconhecia. O IM permitirá, justamente, colocar a teoria da ação (racional) no centro da investigação sociológica "this why subsequent generations of social theorists, under Weber's influence, sought to bring about the methodological unification of the social sciences by producing what came to be known as a "general theory of action" - one that would broaden the economic model of action (Stanford Encyclopedia of Philosophy). Sabe-se que Schumpeter foi o primeiro cientista social a usar o termo "individualismo metodológico", para se referir justamente a Max Weber, em artigo publicado em 1909 no Quarterly Journal of Economics intitulado "On the Concept of Social Value" (Davis, p. 35).

De acordo com Schumpeter, para algumas questões sociais e políticas não há escolha, senão partir da totalidade social. Mas, quando se trata do fenômeno de mercado, só se pode começar a análise a partir do indivíduo. Isto significa que a definição do método depende do objeto: para se explicar o desenvolvimento econômico há que se recorrer ao individualismo metodológico. Em uma interessante passagem do livro de John Davis, The Theory of the Individual in Economics, o autor 
tenta reconstituir o significado que Schumpeter atribuía a este termo: "Embora o sentido original do terno IM de Schumpeter significasse que as explicações no nível dos indivíduos fossem apenas formalmente informativas em economia, individualismo metodológico no sentido contemporâneo tem um significado prescritivo em recomendar que a explicação econômica de entidades supraindividuais possam ser reduzidas a ou traduzidas em decisões e ações individuais” (Davis, p. 36).

Schumpeter analisa o empreendedor fazendo uso do individualismo como recurso metodológico para explicar teoricamente a ação pioneira e inovadora em suas causas e desencadeamentos. Repito: a ênfase não está no indivíduo enquanto entidade empírica, mas enquanto ente portador de sentido da ação (social) que se quer interpretar. Se ambos trabalham com os mesmos recursos, quais sejam, IM e tipo ideal, a crítica feita a Schumpeter haveria de ser, ao menos em alguma medida, aplicável a Weber. Contudo, em que sentido poder-se-ia afirmar que Weber, um dos fundadores da sociologia, dá ênfase ao indivíduo em detrimento das instituições?

\section{CONCLUSÃO}

Entre os comentadores de Schumpeter há uma singela, mas importante, convergência: a de que este autor reconhece que ambientes e instituições criam novas oportunidades. Contudo, dirão, a maneira como ele acentua as resistências de caráter institucional que o empreendedor sofre ao inovar, faz sobressair o empreendedor enquanto indivíduo, em detrimento do papel das instituições na inovação (Devine, 2002; Aldrich, 2005). De fato, algumas perguntas de pesquisa nos dirigiriam para caminhos diferentes daqueles que Schumpeter apresenta como decorrência de sua teoria, como por exemplo: qual é a influência dos ambientes nas organizações? De que modo conformidade e isomorfismo contribuem para explicar sobrevivência ou mudança organizacional? Estas são, como se sabe, perguntas típicas da teoria neoinstitucional. Porém, uma teoria da ação condicionada, seja pela estrutura social, seja pelas instituições, perde a dimensão da intencionalidade dos agentes e o empreendedor schumpeteriano - como vimos - preserva uma certa autonomia das estruturas sociais: ele não se define pela posição de classe, não segue tradições etc. Assim, a dimensão "estruturante" da teoria do empreendedor schumpeteriano é a do conflito e, por conseguinte, da intencionalidade e capacidade de ação. De fato, seu modelo pressupõe uma teoria da ação que, segundo nosso entendimento, é de cunho weberiano.

Seria incorreto afirmar que Schumpeter desconsidere as instituições. Mas, certamente sua abordagem difere daquela da teoria institucional. O motivo é simples: o empreendedor não se conforma a pressões institucionais. Ao contrário, ele as desafia, as supera e implanta outros padrões. Ele cria, portanto, condições para a formação de um novo campo institucional, mas o faz justamente porque, no momento anterior, o desafiou. Obviamente seria também incorreto pressupor que agir contra as instituições possa significar não levá-las em conta (do ponto de vista do empreendedor) ou não incorporá-las na análise (do ponto de vista do sujeito do 
conhecimento). Claramente, agir segundo regras institucionalizadas não é empreender. No entanto, o empresário schumpeteriano age socialmente, também nos moldes weberianos. Uma pequena digressão: do mesmo modo que, para Weber, um ladrão age socialmente porque, ao planejar um roubo evitará ser capturado (portanto leva em conta o sistema normativo que o impede de roubar e o sistema jurídico e prisional que poderá detê-lo etc.), o empreendedor schumpeteriano - ao se antepor e desafiar as instituições (as visões tradicionais, as rotinas da empresa etc.), implantará um novo padrão cognitivo e organizacional ao ser bem-sucedido no final deste processo.

Nesse sentido é preciso destacar dois pontos: 1) a ideia de ação (mediada por interesses) é inerente ao conceito de empreendedor; 2) a ação do empreendedor é social na mesma perspectiva weberiana: porque leva em conta o(s) outro(s) ou seja, uma pluralidade de agentes determinados ou indeterminados (inclusive instituições). Lembramos que, para Weber, agir seguindo uma regra é uma ação social do mesmo modo que agir contrariando a regra também o é. Para o nosso argumento, isso significa que uma ação que resulta em conflito com instituições sociais e/ou econômicas, deve ser compreendida como uma ação socialmente orientada. Segundo Swedberg, Weber trabalha com uma dimensão fundamental da Sociologia Econômica: interesse. "A principal diferença entre a nova sociologia econômica e Weber é que o papel dos interesses é acentuado no último, mas não nos primeiros. A unidade de análise é a ação orientada por interesses, utilidade e orientada para outros atores. $\mathrm{O}$ fato de que outros atores são levados em conta, que sentimentos influenciam a ação e que interesses podem ser materiais, assim como ideais, faz da abordagem weberiana mais flexível e sofisticada" (Granovetter e Swedberg, 1992, p. 89). No nosso entender, o mesmo se aplica a Schumpeter.

Para finalizar, gostaríamos de voltar ao começo deste artigo. Iniciamos este trabalho chamando atenção para a "elasticidade" do conceito de empreendedor / empreendedorismo: "próprio negócio"; "pequenas empresas emergentes", "capacidade de reconhecimento de novas oportunidades", "criação de novas organizações”, "inovação" etc. Geralmente, os conceitos são empíricos e descritivos, "utilizados" sem considerações acerca de suas eventuais dimensões teóricas e conceituais. Também por teste motivo, Schumpeter ainda hoje é uma referência central, seja pela profundidade teórica de seu modelo, que liga o conceito de empreededorismo à teoria do desenvolvimento econômico, seja pela dimensão institucional incorporada a partir de uma perspectiva de conflito / interesses, dimensão esta fundamentada em uma teoria da ação social.

$\mathrm{Na}$ medida em que Schumpeter enfatiza a esfera dos conflitos entre o empreendedor e as instituições, ele opera uma espécie de deslocamento analítico na dimensão institucional: do empresário "produzido" / "fruto" das instituições, para o empresário que age, resiste e luta contra elas (sem o que não se viabilizam inovações radicais). Como resultado desse processo, o empresário bem-sucedido é aquele que vence as resistências e impõe novos padrões de combinação dos meios de produção. Destruição de velhos padrões gera desequilibro nas instituições econômicas, por um lado, assim como pressões para novos padrões de conformidade — até atingir 
o ponto de uma nova situação de equilíbrio - por outro. Portanto, se consideramos ainda válidos os ensinamentos de Schumpeter, as pesquisas sobre empreendedorismo haveriam de levar em conta os seguintes aspectos: inovação (pioneirismo) na dimensão cognitiva e conflito institucional, procurando sobretudo abordar mudanças institucionais de caráter radical e não adaptativo. Não é o caso de evitar a questão: quais são as condições institucionais que promovem e facilitam o empreendedorismo, mas começar e enfatizar uma outra, qual seja, quais são as barreiras institucionais que a ele se opõem?

\section{REFERÊNCIAS BIBLIOGRÁFICAS}

ALDRICH, Howard. "Entrepreneurship”. In SMELSER, Neil and SWEDBERG, Richard. The Handbook of Economic Sociology. Princeton University Press: Princeton, 2005.

BOUDON, Raymon. Tratado de Sociologia - São Paulo: Zahar, 1995

CAMIC, Charles, GOSKI, Philip and TRUBEK, David (editors). Max Weber's Economy and Society - A critical companion. Stanford: Stanford University Press, 2005

DAIRES, John B. (2003) The theory of the indidual. Londres: Routledge.

DEVINE, Pat. "The Institutional Context of Entrepreneurial Activity". In DEVINE, Pat e FIKRET, Adanan, Fikret. Economy and Society - Money, capitalism and transition. London: Black Rose Books, 2002.

DURKHEIM, Emile. As Regras do Método Sociológico. São Paulo: Companhia Editora Nacional, 1972.

GRANOVETTER, M. e SWEDBERG, R. The Sociology of Economic Life. San Francisco: Westview Press, 1992

MARTINELLI, Alberto. "Entrepreneurship and Management". In SMELSER, Neil and SWEDBERG, Richard (editors). The Handbook of Economic Sociology. Princeton: Princeton University Press.1994.

SCHUMPETER, Joseph. "O Fenômeno Fundamental do Desenvolvimento Econômico". In A Teoria do Desenvolvimento Econômico. Rio de Janeiro: Nova Cultural, 1985

SHIONOYA Y. Schumpeter and the Idea of Social Science. Cambridge: Cambridge University Press, 1977.

SILVA, Marcos Fernandes. “A epistemologia da economia teórica de Schumpeter”. Revista de Economia Política, n. 22, janeiro, Março, 2002.

SMELSER, Neil e SWEDBERG, Richard (editors) The Handbook of Economic Sociology. Princeton: Princeton University Press, 1994

SOMBART, Werner. "O homem econômico moderno”. In IANNI, Octávio. Teorias da Estratificação Social. São Paulo: Editora Nacional, 1973

SOUZA, Eda e GUIMARÃES, Tomás (orgs.) Empreendedorismo - Além do Plano de Negócio. São Paulo: Editora Atlas, 2005.

SWEDBERG, Richard, Max Weber e a Ideia de Sociologia Econômica. Rio de Janeiro: Editora UFRJ, 2005.

SWEDBERG, Richard, The Economic Sociology of Capitalism - Weber and Schumpeter Journal of Classical Sociology. London: Sage Publication, 2002

SWEDBERG, Richard, The Max Weber Dictionary. Stanford: Stanford University Press, 2005.

WEBER, Max. A Ética Protestante e o Espírito do Capitalismo. São Paulo: Companhia das Letras, 2004.

WEBER, Max.Economia e Sociedade. Brasília: Editora UNB, 2000

WEBER, Max. Metodologia das Ciências Sociais. São Paulo: Cortez Editora 2001. 